\title{
Long all-active monolithic mode-locked lasers with surface-etched bragg gratings
}

\author{
Larsson, David; Yvind, Kresten; Hvam, Jørn Märcher
}

Published in:

IEEE Photonics Technology Letters

Link to article, DOI:

10.1109/LPT.2007.905680

Publication date:

2007

Document Version

Publisher's PDF, also known as Version of record

Link back to DTU Orbit

Citation (APA):

Larsson, D., Yvind, K., \& Hvam, J. M. (2007). Long all-active monolithic mode-locked lasers with surface-etched bragg gratings. IEEE Photonics Technology Letters, 19(21), 1723-1725.

https://doi.org/10.1109/LPT.2007.905680

\section{General rights}

Copyright and moral rights for the publications made accessible in the public portal are retained by the authors and/or other copyright owners and it is a condition of accessing publications that users recognise and abide by the legal requirements associated with these rights.

- Users may download and print one copy of any publication from the public portal for the purpose of private study or research.

- You may not further distribute the material or use it for any profit-making activity or commercial gain

- You may freely distribute the URL identifying the publication in the public portal

If you believe that this document breaches copyright please contact us providing details, and we will remove access to the work immediately and investigate your claim. 


\title{
Long All-Active Monolithic Mode-Locked Lasers With Surface-Etched Bragg Gratings
}

\author{
David Larsson, Kresten Yvind, and Jørn M. Hvam
}

\begin{abstract}
We have fabricated 4.4-mm-long monolithic InAlGaAsP-InP mode-locked lasers with integrated deeply surface etched distributed Bragg reflector (DBR) mirrors. The lasers produce 3.7-ps transform-limited Gaussian pulses with 10-mW average output power and 250-fs absolute timing jitter. The performance of the DBR lasers is compared to the performance of Fabry-Pérot mode-locked lasers from the same wafer and to the performance of earlier reported long monolithic DBR mode-locked lasers and is found to be better.
\end{abstract}

Index Terms-Distributed Bragg reflector (DBR), mode-locked laser diode, optical communications.

\section{INTRODUCTION}

$\mathbf{M}$ ONOLITHIC mode-locked lasers (MMLLs) are attractive as compact pulse sources in high-speed optical communication systems [1], in microwave photonics [1], and in high-speed optical sampling [2]. Distributed Bragg reflectors (DBRs) or other types of filters are needed in these lasers to control the spectral bandwidth, the center wavelength, and to obtain repetition rate tuning of the pulses [4]. DBRs also offer the possibility of further integration with other optical elements, e.g., modulators, amplifiers, and detectors.

There are only a few reports on long $(\sim 10 \mathrm{GHz})$ MMLLs with integrated wavelength-selective filters at a wavelength of $1.55 \mu \mathrm{m}$. The ones reported suffer from low output power $(<1 \mathrm{~mW})$ [3], [4], and long pulses (6.1 ps) [3], ( $\geq 9 \mathrm{ps})$ [4], [5]. Furthermore, detailed noise characterization has not been reported before. We present a laser that combines an active material design for short pulses with high power and low noise [6], with a deeply surface-etched DBR. To our knowledge, this is the first time an MMLL is integrated with a surface-etched DBR. The potential advantages of surface-etched DBRs compared to conventional regrown DBRs are large index contrasts, Al-containing layers can be used for and below the grating without the risk of oxidation, the difficult regrowth on the corrugated surface is omitted, and finally the cost is reduced since no in-house epitaxial growth is necessary. Surface-etched DBRs have been reported for single-mode lasers (mostly GaAs-based) by the University of Illinois with good results, e.g., $K>100 \mathrm{~cm}^{-1}$ in [7].

Manuscript received May 30, 2007; revised July 4, 2007. This work was supported in part by the Danish Technical Research Council SCOOP program and the Talent Project 26-04-0060.

The authors are with the COM-Department of Communications, Optics and Materials, NanoDTU, Technical University of Denmark, 2800 Kgs. Lyngby, Denmark (e-mail: dla@com.dtu.dk).

Color versions of one or more of the figures in this letter are available online at http://ieeexplore.ieee.org.

Digital Object Identifier 10.1109/LPT.2007.905680

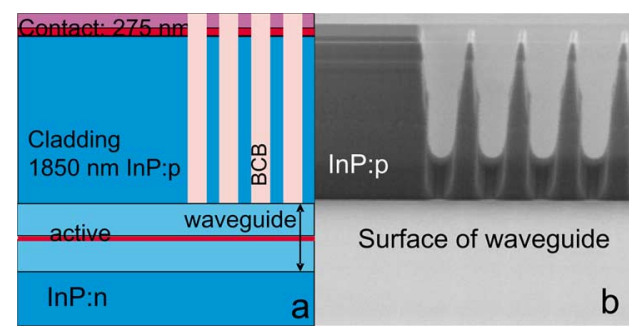

Fig. 1. (a) Schematic laser cross section. (b) SEM micrograph of ridge and grating after cyclic dry etch and following wet etch in concentrated $\mathrm{H}_{2} \mathrm{SO}_{4}$.

\section{DESIGN AND FABRICATION}

The epitaxial structure is similar to [6], with one 7-nm $\mathrm{In}_{0.29} \mathrm{Ga}_{0.71} \mathrm{As}_{0.90} \mathrm{P}_{0.10}$ quantum well as the gain material and $\mathrm{Al}_{0.16} \mathrm{Ga}_{0.31} \mathrm{In}_{0.53} \mathrm{As}$ barriers, and is grown in a single epitaxial step. The integration of the DBR is performed by surface-etching the grating and the ridge simultaneously. A combined grating and ridge mask in $200-\mathrm{nm} \mathrm{SiO}_{2}$ is defined by first e-beam lithography and then UV lithography. The 2.4- $\mu \mathrm{m}$-wide ridge and the 364-nm grating trenches (third-order $50 \%$ duty cycle) are then etched to 2125 -nm depth with a $\mathrm{CH}_{4}-\mathrm{H}_{2}(1: 4)$ reactive ion etching (RIE) (pressure: 25 mTorr; $\mathrm{V}_{\text {dcbias }}: 430 \mathrm{~V}$; total flow: $26.5 \mathrm{sccm}$ ) combined with cycles of $\mathrm{O}_{2}$ (cycle time: $3 / 0.5 \mathrm{~min}$ ) to remove polymer deposition. The RIE is followed by a 1-min wet etch in concentrated $\mathrm{H}_{2} \mathrm{SO}_{4}$ to remove RIE-damaged InP. Fig. 1 shows that there is a slower etching in the middle of the trenches when the aspect ratio becomes high enough. We believe this lag effect is caused by shadowing of ions and neutral radicals as in the Si-RIE case [8]. The ridge height can be lowered to remove the lag but this increases the optical losses in the contact layers because of the weakly confined mode needed for good mode-locking. A simple improved design would be to use fourth-order gratings where the increased index difference compensates the reduced number of reflections and increases the total reflection. An even better solution would be to grow a slightly lower ridge $(\sim 200 \mathrm{~nm})$ with the combination of an epitaxial etch-stop layer (AlInAs).

Cyclotene 3022-35 is used for passivation and for support of the pillars. The chips are cleaved to a length of $\sim 4.4 \mathrm{~mm}$, and mounted in the same way as in [6]. After mounting, a 98\% high reflection (HR) coating is applied to the absorber facet. Furthermore, a $\sim 10^{-4}$ antireflection (AR) coating is applied to the DBR facet to ensure low facet reflections. The DBR section is also contacted and driven in forward bias during all modelocking experiments to compensate for the losses in that section. 


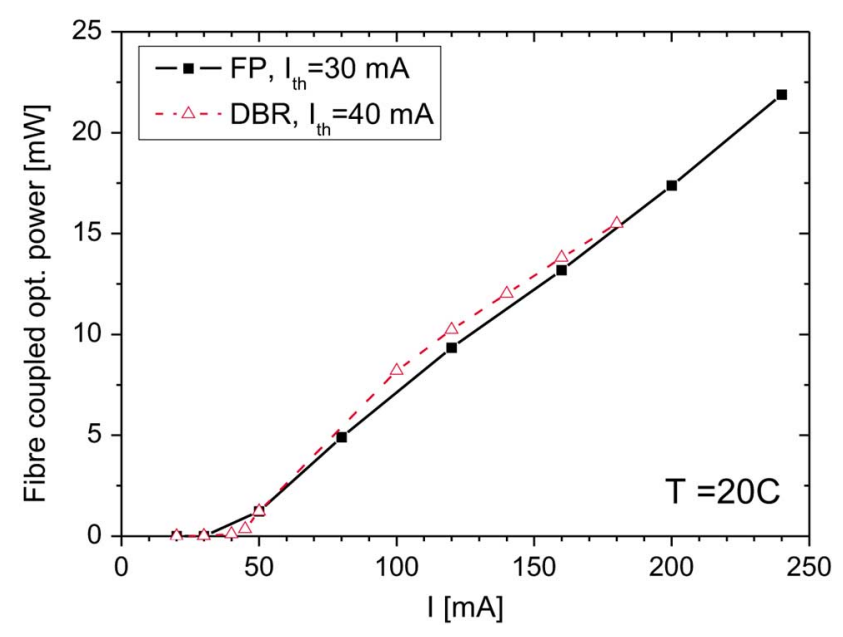

Fig. 2. Typical CW fiber-coupled output power from coated DBR laser and FP laser with 5\% AR coating.

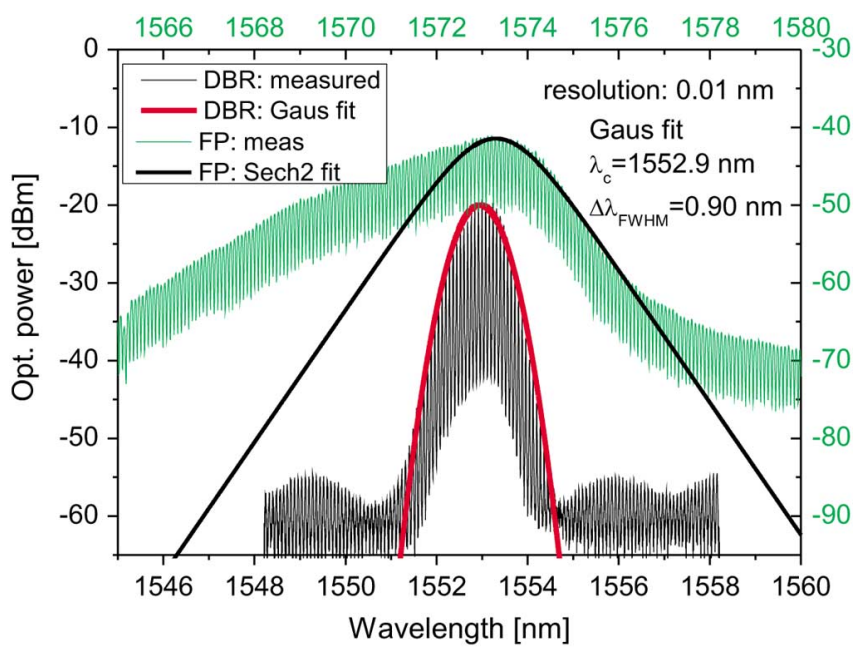

Fig. 3. Attenuated time-averaged optical spectra from the passive mode-locked FP (green) and DBR (black) lasers. Top x-axis and left y-axis corresponds to the FP trace. Full-width at half-maximum (FWHM) of the $\mathrm{Sech}^{2}$ fit is $1.8 \mathrm{~nm}$. The 12-dB higher modulation depth for the DBR laser indicates better mode-locking.

\section{MEASUREMENTS}

The average threshold current for the five DBR lasers that were mode-locked was $40 \mathrm{~mA}\left(J_{\mathrm{th}}: 0.45 \mathrm{kA} / \mathrm{cm}^{2}\right)$ after both coatings had been applied, and the fiber-coupled output power in continuous-wave $(\mathrm{CW})$ mode reached more than $15 \mathrm{~mW}$. A Fabry-Pérot (FP) laser from the same wafer was made as reference and given an HR coating and a 5\% AR coating. Typical light output-current $(L-I)$ curves for DBR and FP lasers are shown in Fig. 2.

The 145- $\mu \mathrm{m}$-long Bragg gratings are designed to have a center wavelength of $1550 \mathrm{~nm}$ and the measured center wavelengths were $1553 \pm 2 \mathrm{~nm}$ (Fig. 3), a variation much smaller than the $15-\mathrm{nm}$ variation of the gain peak across the wafer. The grating reflectivity versus wavelength is calculated from measurements of the modulation depth of the longitudinal modes from both facets (grating facet AR coated and other facet uncoated). The measured spectral widths of the gratings are $\sim 2 \mathrm{~nm}$ and the measured peak reflection is $\sim 1 \%$. The low

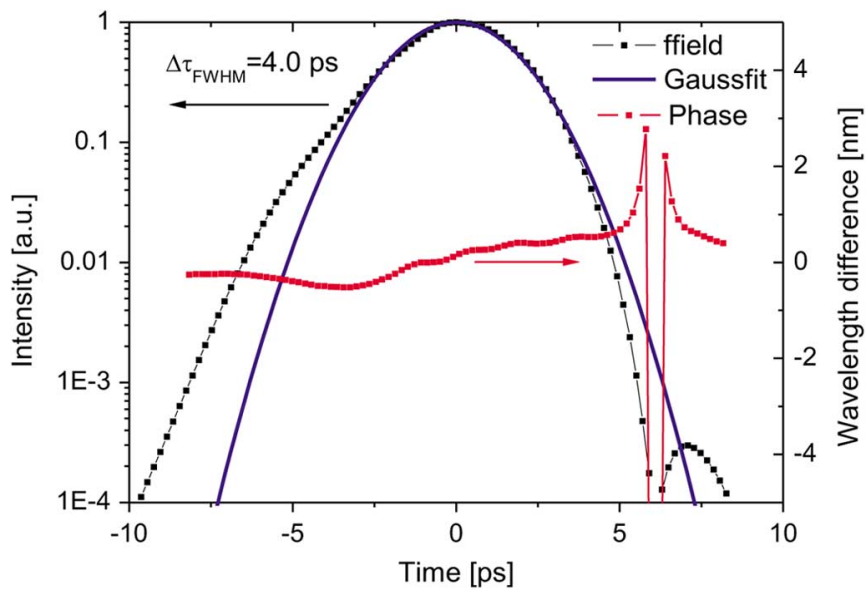

Fig. 4. Field intensity and temporal phase retrieved from FROG data $(128 \times 128$ points; FROG error 0.008) from DBR laser, corresponding to the spectrum in Fig. 2. Blue line is a Gaussian fit. Operating conditions: gain current $81 \mathrm{~mA}$, grating voltage $1.0 \mathrm{~V}$, absorber voltage $-2.53 \mathrm{~V}$. $(\Delta \tau \Delta \nu)_{\mathrm{FWHM}}=0.48$ obtained from the FROG data.

reflection can be explained by the fact that the duty cycle has not been properly transferred from the resist to the bottom of the etch, and by the mentioned lag effect.

Under uniform forward injection, the lasers are single-mode, while a negative absorber bias of more than $-2.2 \mathrm{~V}$ results in passive mode-locking with a Gaussian spectrum and a background suppressed by $>35 \mathrm{~dB}$ (Fig. 3). The fiber-coupled power during mode-locking typically exceeds $5 \mathrm{~mW}$ with a coupling loss of $3 \mathrm{~dB}$. Frequency-resolved optical gating (FROG) was used to measure the pulse shapes (Fig. 4) and typical 3-dB widths ranged between 3.7 and $6 \mathrm{ps}$, depending on bias conditions, with time-bandwidth products of $0.4-0.5$ (with $6.3 \mathrm{ps} / \mathrm{nm}$ added linear dispersion in single-mode fiber). The uncompressed pulsewidths from the FP laser were measured to be 2 ps in accordance with our earlier reported FP laser results [9]. The spectra of the FP laser show the same broad high-energy tail as many other reported monolithic FP MLLs based on quantum wells [9], [10]. Thus, for a fair comparison of the time-bandwidth product, we have chosen the $1 / e$ widths instead of the more common half-maximum widths. The $\mathrm{TBP}_{1 / e}$ is 5 for the FP laser and 2 for the DBR (uncompressed pulses).

Hybrid mode-locking is performed by modulating the absorber bias with a $\sim 9.9-\mathrm{GHz}$ sinusoid from a synthesizer (R\&S SMR40), amplified to $26 \mathrm{dBm}$. The absorber bias needs to be increased to $\sim-5 \mathrm{~V}$ to obtain good hybrid mode-locking. No major change in pulsewidth or spectral width could be observed with the addition of the RF signal, indicating that the filter limits the pulse shortening. By reducing the RIE lag, it is possible to use a shorter grating with a wider filter and thereby obtain as short pulses as for the FP lasers. The RF spectrum becomes much narrower in hybrid operation, indicating a good lock to the modulating synthesizer signal. An upper limit to the timing jitter is measured with an RF spectrum analyzer from the phase noise in the fundamental RF line as outlined in [11] [Fig. 5(a)]. The phase-noise plateau of the DBR laser is $-120 \mathrm{~dB} / \mathrm{Hz}$ and would produce a jitter of $200 \mathrm{fs}(\rightarrow 80 \mathrm{MHz})$ if the synthesizer were noiseless. Integrating the measured phase noise according to the 

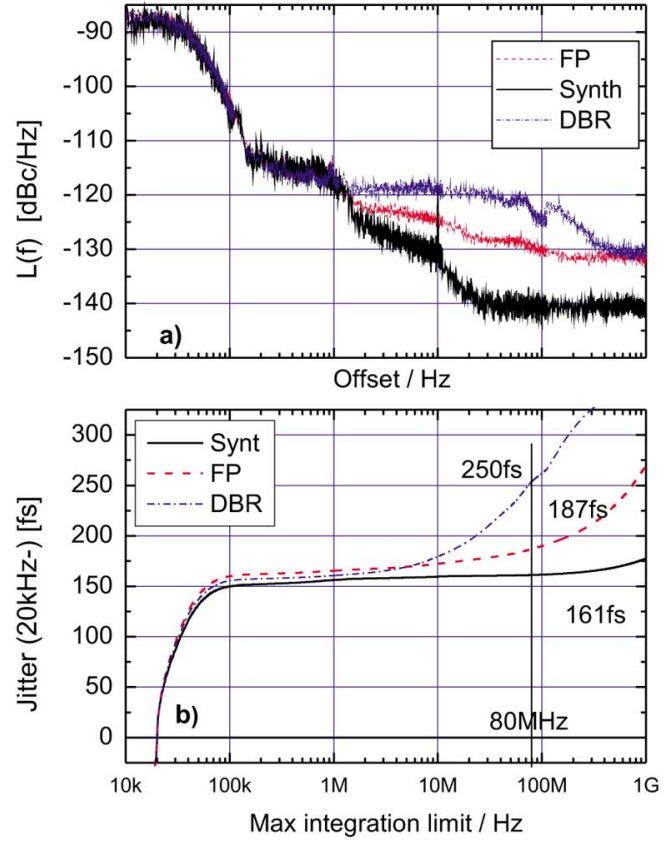

Fig. 5. (a) Absolute single-sideband phase noise for hybrid mode-locked DBR and FP laser and the driving synthesizer. (b) Absolute integrated rms timing jitter integrated from $20 \mathrm{kHz}$ to an upper limit.

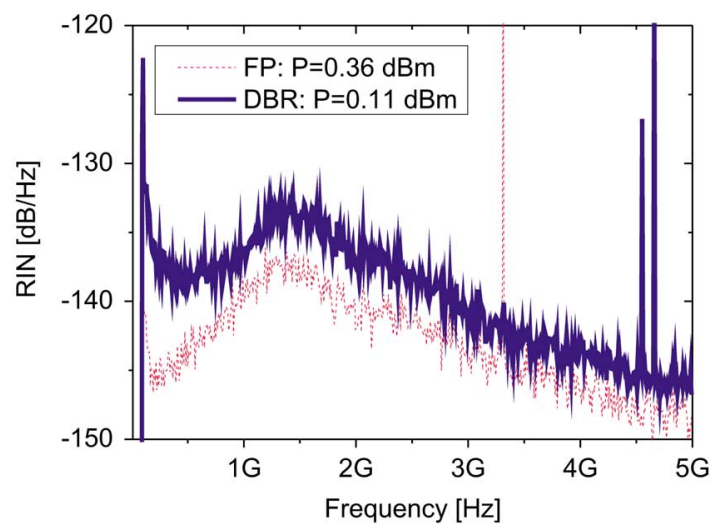

Fig. 6. RIN spectra for DBR and FP lasers under hybrid operation. The spurs at $\sim 3.5$ and $\sim 4.5 \mathrm{GHz}$ reoccur at the same frequencies for other lasers and for other biases and are attributed to measurement pick-ups.

specifications by ITU-T ( $20 \mathrm{kHz}-80 \mathrm{MHz})$ [12] results in an absolute root-mean-square (rms) timing jitter of $250 \mathrm{fs}$, of which the synthesizer contributes the most below $1 \mathrm{MHz}$, Fig 5(b).

Fig. 6 presents the amplitude noise of the same lasers. The slightly larger phase and amplitude noise levels in the DBR laser compared to the FP laser can at least partly be explained by the higher threshold current, which in turn is caused by the low reflectivity of the grating, which again can be improved by simple means.

\section{SUMmARY}

We have designed and fabricated the first MMLLs with deeply surface-etched Bragg reflectors and presented complete characterization of the mode-locking, including phase noise and relative intensity noise (RIN) spectra. The DBR lasers are more suitable for optical fiber communications than $10-\mathrm{GHz}$ FP lasers from the same wafer, and to our knowledge, also outperform the best earlier 10-GHz DBR-MMLLs [4], [5] made by regrowth. We believe that we can improve the grating and thereby the lasers considerably by small adjustments to the existing epitaxial design and also by improving our processing. We believe that such single epitaxy lasers will be able to produce high-quality pulses as short as $1 \mathrm{ps}$, with transform-limited spectra, with average fiber-coupled powers of $10 \mathrm{~mW}$ and with timing jitter below $100 \mathrm{fs}$. This is a suitable candidate for the commercialisation of monolithic semiconductor mode-locked lasers.

\section{ACKNOWLEDGMENT}

The authors acknowledge P. Shi for valuable help with the e-beam process.

\section{REFERENCES}

[1] E. A. Avrutin, J. H. Marsh, and E. L. Portnoi, "Monolithic and multigigahertz mode-locked semiconductor lasers; Constructions, experiments, models and applications," IEE Proc. Optoelectron., vol. 147, pp. 251-278, 2000.

[2] S. Diez, R. Ludwig, C. Schmidt, U. Feiste, and H. G. Weber, "160-Gb/s optical sampling by gain-transparent four-wave mixing in a semiconductor optical amplifier," IEEE Photon. Technol. Lett., vol. 11, no. 11, pp. 1402-1404, Nov. 1999

[3] I. Ogura, H. Kurita, T. Sasakiand, and H. Yokoyama, "Precise operation-frequency control of monolithic mode-locked laser diodes for high-speed optical communication and all-optical signal processing," Opt. Quantum Electron., vol. 33, pp. 709-725, 2001.

[4] E. Zielinski, E. Lach, J. Bouayad-Amine, H. Haisch, E. Kuhn, M. Schilling, and J. Weber, "Monolithic multisegment mode-locked DBR laser for wavelength tunable picosecond pulse generation," IEEE $J$. Sel. Topics Quantum Electron., vol. 3, no. 2, pp. 230-232, Apr. 1997.

[5] P. Hansen, G. Raybon, U. Koren, B. I. Miller, M. G. Young, M. Chien, C. A. Burrus, and R. C. Alferness, "5.5-mm long InGaAsP monolithic extended-cavity laser with an integrated Bragg-reflector for active mode-locking," IEEE Photon. Technol. Lett., vol. 4, no. 3, pp. 215-217, Mar. 1992

[6] K. Yvind, D. Larsson, L. J. Christiansen, C. Angelo, L. K. Oxenløwe, J. Mørk, D. Birkedal, J. M. Hvam, and J. Hanberg, "Low-jitter and highpower $40 \mathrm{GHz}$ all-active mode-locked lasers," IEEE Photon. Technol. Lett., vol. 16, no. 4, pp. 975-977, Apr. 2004

[7] G. M. Smith, J. S. Hughes, R. M. Lammert, M. L. Osowski, G. C. Papen, J. T. Verdeyen, and J. J. Coleman, "Wavelength-tunable asymmetric cladding ridge-waveguide distributed Bragg reflector lasers with very narrow linewidth," IEEE J. Quantum Electron., vol. 32, no. 7, pp. 1225-1229, Jul. 1996.

[8] H. Jansen et al., "RIE lag in high aspect ratio trench etching of silicon," Microelectron. Eng., vol. 35, no. 1-4, pp. 45-50, Feb. 1997.

[9] K. Yvind, D. Larsson, L. J. Christiansen, J. Mørk, J. M. Hvam, and J. Hanberg, "High-performance $10 \mathrm{GHz}$ all-active monolithic modelocked semiconductor lasers," Electron. Lett., vol. 40, no. 12, pp. 735-737, Jun. 2004.

[10] A. Bryce, F. Camacho, P. Cusumano, and J. H. Marsh, "CW and modelocked integrated extended cavity lasers fabricated using impurity free vacancy disordering," IEEE J. Sel. Topics Quantum Electron., vol. 3, no. 3, pp. 885-892, Jun. 1997.

[11] D. von der Linde, "Characterization of the noise in continuously operating mode-locked lasers," Appl. Phys. B, vol. 39, no. 4, pp. 201-217, Apr. 1986.

[12] The Control of Jitter and Wander Within the Opt. Transp. Network (otn), ITU-T Rec. G.8251, Nov. 2001. 